\title{
THE CISTERNAL PRESSURE IN CONGESTIVE HEART FAILURE AND ITS BEARING ON ORTHOPNEA
}

\author{
By WILLIAM GROCE HARRISON, JR. \\ (From the Department of Internal Medicine, Emory University School of Medicine, Grady \\ Hospital (colored unit), Atlanta)
}

(Received for publication July 12, 1933)

Various theories concerning the cause of orthopnea have been advanced, but sufficient proof for accepting any one explanation of this phenomenon has not been offered.

As an excellent review of the literature on orthopnea has been given by Ernstene and Blumgart (1), only a few of the theories will be mentioned here. Sahli (2) thought that the greater use of the accessory muscles of respiration, the accumulation of blood in the lower extremities leading to diminished pulmonary congestion, and a decrease in the work of the heart along with the relief of venous congestion of the brain and of the respiratory center by the action of gravity were the fundamental factors responsible for the sitting posture in orthopnea. Haldane, Meakins and Priestly (3) expressed the belief that a decrease in anoxemia of the respiratory center and a better oxygenation of the arterial blood leaving the lungs were largely responsible for the greater comfort in breathing that a patient with cardiac disease exhibits in the upright position.

Christie and Beams (4) reported careful studies of the vital capacity of a large number of normal subjects and of patients with cardiac disease. They found that, although the vital capacity was decreased when the normal person went from sitting to prone position, this decrease was much greater in patients with cardiac disease accompanied by orthopnea. They, therefore, inferred that the diminished vital capacity of the lungs in the prone position is the main cause of orthopnea.

Ernstene and Blumgart (1), however, observed orthopnea of necessity in patients in whom the vital capacity of the lungs was not significantly increased by changing from the recumbent to the sitting position. They demonstrated furthermore a parallelism between the height of venous pressure and the degree of orthopnea in twenty-two patients with uncomplicated myocardial failure. They were inclined to the view that lowering of cerebral venous pressure in the sitting posture is the primary factor in reducing the respiratory discomfort.

In a recent series of studies Harrison (5) demonstrated an increase in cerebrospinal fluid pressure in patients with cardiac failure and the parallelism of venous and spinal fluid pressure in this condition. $\mathrm{He}$ 
also observed the effect of treating by means of spinal drainage patients having congestive heart failure. It was noted in observations not yet published that after spinal drainage was performed on individuals with orthopnea many of these patients were able to breathe more comfortably in the recumbent position, although the vital capacity of the lungs had not been significantly altered by this procedure. A study was also made of the cisternal pressure in the upright and recumbent positions in one normal individual, and in one patient with congestive heart failure, and the relation of cisternal pressure to orthopnea was discussed. In the present paper a larger group of such studies is reported.

\section{The cisternal pressure in patients without cardiac disease}

While performing routine lumbar punctures on patients suspected of having syphilis an opportunity was offered to measure the cisternal pressure and the spinal fluid pressure in the sitting and prone positions in five patients, none of whom had any evidence of cardiac disease. A U-shaped glass manometer filled with normal saline was used to make the readings of cisternal pressure. The readings of lumbar spinal fluid pressure were taken with an Ayer water manometer. Venous pressures were determined by the direct method of Moritz and Tabora observing the usual precautions. The vital capacity, the arterial blood pressure, and the pulse and respiration rates were likewise recorded in both positions. (Table 1.)

The systemic venous pressure, as measured at the elbow, was found to be slightly higher in the upright than in the recumbent position. The lumbar spinal fluid pressure was much greater in the sitting position. The cisternal pressure (which ranged from -22 to +17 ) was on the other hand much lower in the sitting position, and in one individual was below zero. The average arterial blood pressure and pulse rate were slightly greater in the sitting position, but neither the blood pressure nor pulse or respiration rates showed marked consistent changes; on the other hand in all instances the vital capacity was slightly increased in the sitting position.

\section{The cisternal pressure in patients with congestive heart failure}

An opportunity was offered to carry out similar observations on five patients who had either syphilitic aortic insufficiency or hypertensive heart disease with congestive failure, while attempts were being made to give relief by spinal drainage. Similar measurements were made in the manner described above. All observations on any one patient were performed on the same day. ${ }^{1}$ (Table 2.)

1 The cisternal pressure recorded was slightly lower in some instances and the spinal fluid pressure lower in others than they should have been because in some cases the spinal fluid pressure was taken first while in others the cisternal pressure was measured first. 
WILLIAM GROCE HARRISON, JR.

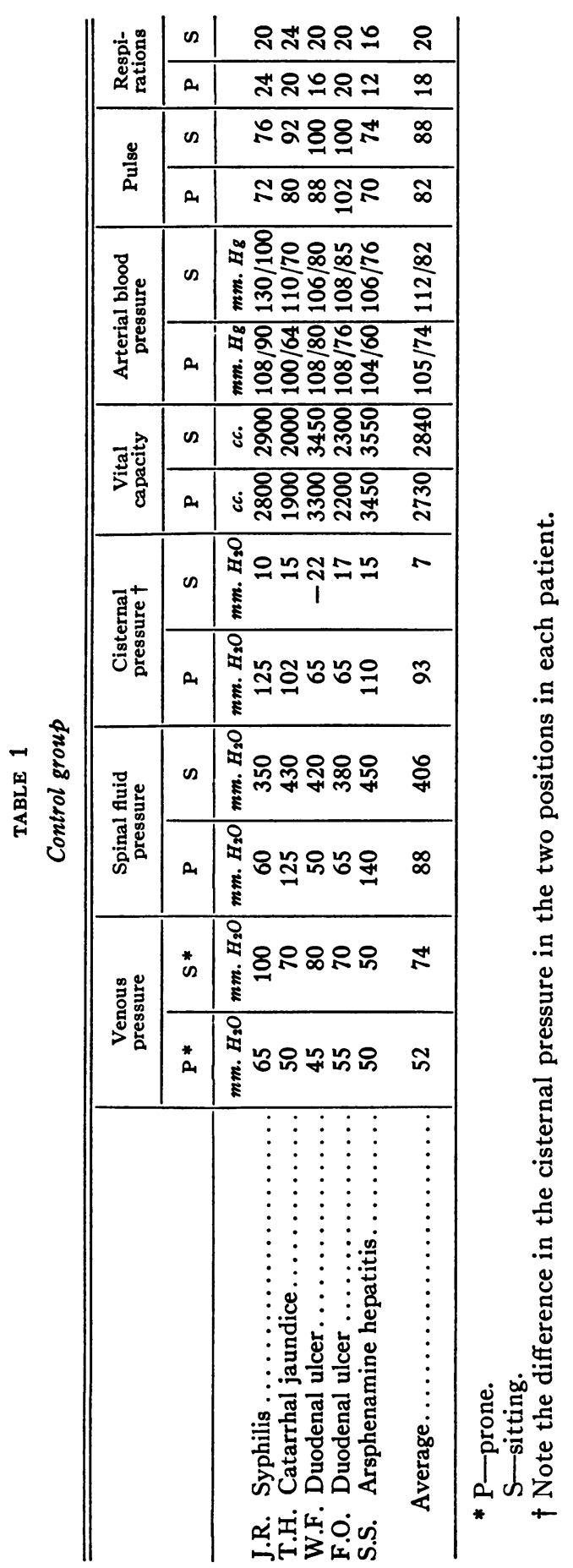




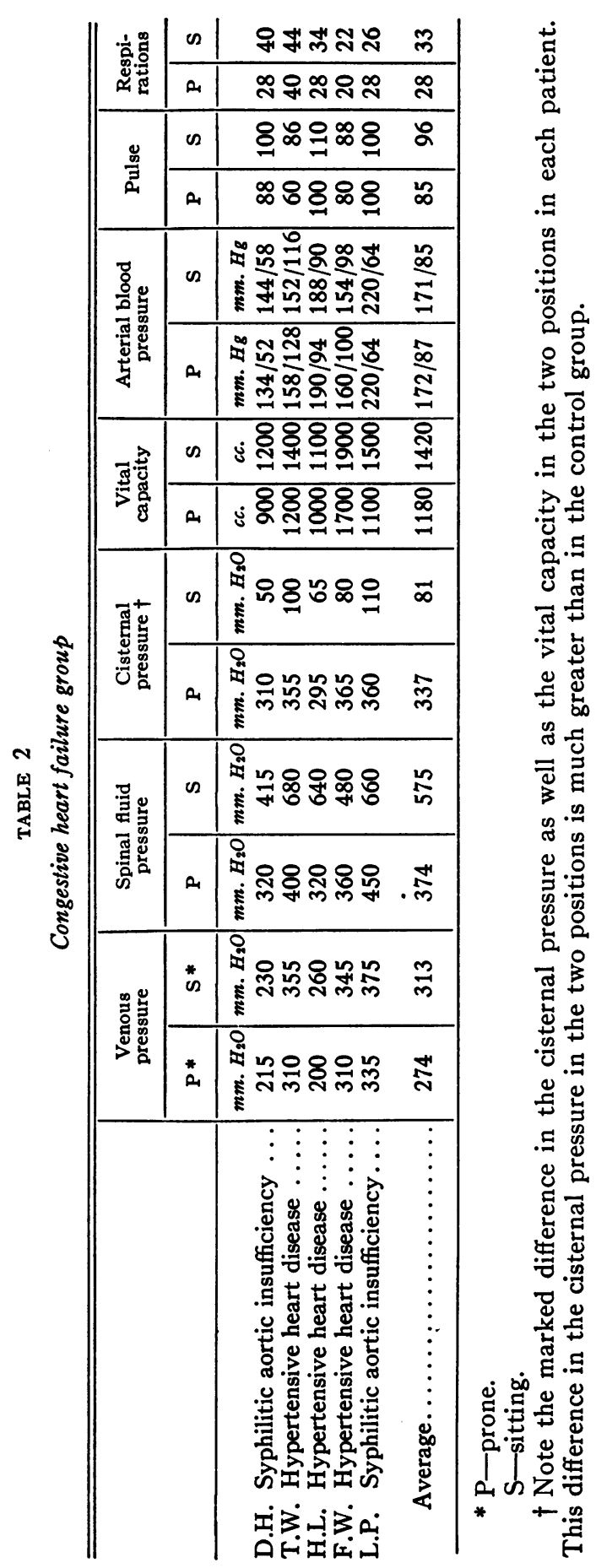


The venous pressure, the lumbar spinal fluid pressure, and the cisternal pressure in each position were found to be much greater in the patients with cardiac disease than in the normal individuals. The venous and the lumbar spinal fluid pressures in the patients with cardiac disease were also considerably higher in the sitting than in the prone position. As in the first group the cisternal pressure was much less in the upright than in the recumbent position. Although the difference in the cisternal pressure in the two positions in the normal individuals was considerable, in the patients with cardiac disease this difference was much greater and averaged $256 \mathrm{~mm}$. water. The arterial blood pressure, and pulse and respiration rates as in the first group showed no marked consistent changes between the two positions, although the pulse rate was usually slightly greater in the sitting position. In every case the vital capacity was higher in the sitting than in the prone position and the percentile increase in the vital capacity was greater in this group than in the patients without cardiac disease.

\section{COMMENT}

Observations on the cisternal pressure of the normal individual in the sitting position have been rare. Ayer (6) reported the cisternal pressure in the upright position to be below zero. Weed (7) demonstrated the difference in cisternal pressure in animals in the two positions, and Weed and Hughson (8) have shown the close relationship that exists between the cerebrospinal fluid pressure and cerebral venous pressure. It has been shown by Harrison, Cullen, Calhoun, Wilkins and Pilcher (9) that a decrease in vital capacity tends to cause a reflex increase in breathing. That an increase in venous pressure causes a reflex stimulation of respiration has been demonstrated by Harrison, Harrison, Calhoun, and Marsh (10).

Since the vital capacity is less in the prone than in the sitting position in patients with congestive heart failure, this decrease in vital capacity is no doubt one important cause of orthopnea. Furthermore, patients have been observed with slight orthopnea who have a diminution in vital capacity but no significant elevation in venous pressure or in cerebrospinal fluid pressure.

On the other hand, a number of observations point to the conclusion that there is another very important factor not connected with the vital capacity concerned in the production of orthopnea. (1) In the first place, Ernstene and Blumgart observed no parallelism between the percentile reduction of vital capacity and the degree of orthopnea, but did observe a striking parallelism between the height of venous pressure and the degree of orthopnea. (2) Ernstene and Blumgart found that when patients with orthopnea were placed in the recumbent position, simple elevation of the head by flexing it on the thorax produced a 
conspicuous diminution of respiratory distress, although this procedure had no significant effect on the vital capacity of the lungs. (3) Harrison found that, after spinal drainage was performed on individuals with orthopnea, many of these patients were able to breathe more comfortably in the prone position, although the vital capacity showed no significant change after this procedure. It has now been shown that the cisternal pressure is markedly decreased when a patient goes from the prone to the sitting position. It seems probable that this decrease in cisternal pressure along with its accompanying change in cerebral venous pressure explains the three sets of observations just mentioned. Anything that tends to decrease cisternal pressure in a patient with cardiac disease will give additional comfort in breathing. One method of reducing this pressure is to sit the patient up. Another method is to employ spinal drainage. Obviously, venesection is very useful, since it not only decreases venous and spinal fluid pressures, but also increases vital capacity.

As a result of these observations it is believed that, in addition to the increase in vital capacity, the diminished cisternal pressure is an important factor in producing the relief from dyspnea obtained in the sitting position. The mechanism of this effect is as yet unknown.

\section{SUMMARY AND CONCLUSIONS}

A study was made of the cisternal pressure, the lumbar spinal fluid pressure, the systemic venous pressure, the vital capacity, the arterial blood pressure, and the pulse and respiration rates in the recumbent and upright positions in five patients without cardiac disease and in five patients with congestive heart failure.

1. The arterial blood pressure and pulse rate were usually slightly greater in the sitting than in the prone position, but in general the blood pressure, and the pulse and respiration rates showed no marked consistent changes with position in either group.

2. The systemic venous and lumbar spinal fluid pressures were greater in the sitting than in the prone position in each subject, and were much greater in each position in the patients with congestive heart failure than in the patients without cardiac disease.

3. The vital capacity was greater in the sitting than in the prone position in both groups of cases and the percentile increase of vital capacity with change in position was greater in the patients with cardiac disease.

4. The cisternal pressure was much greater in each position in the group with congestive heart failure than in the other group.

5. The cisternal pressure was much less in the upright than in the recumbent posture in each case and this difference in cisternal pressure between the two positions was much greater in patients with congestive heart failure than in those without cardiac disease. 
As a result of these observations it is believed that, in addition to the increase in vital capacity, the diminished cisternal pressure is an important factor in producing the relief from dyspnea obtained in the sitting position. The mechanism of this effect is as yet unknown.

\section{BIBLIOGRAPHY}

1. Ernstene, A. C., and Blumgart, H. L., Arch. Int. Med., 1930, xlv, 593. Orthopnea-Its Relation to the Increased Venous Pressure of Myocardial Failure.

2. Sahli, H., Lehrbuch der klinischen untersuchungs-Methoden. Franz Deuticke, Leipzig, 1894.

3. Haldane, J. S., Meakins, J. C., and Priestley, J. G., J. Physiol., 1919, lii, 433. The Effects of Shallow Breathing.

4. Christie, C. D., and Beams, A. J., Arch. Int. Med., 1923, xxxi, 85. Orthopnea.

5. Harrison, W. G., Jr., Arch. Int. Med., (In press). Cerebrospinal Fluid Pressure and Venous Pressure in Cardiac Failure and the Effect of Spinal Drainage in the Treatment of Cardiac Decompensation.

6. Ayer, J. B., The Human Cerebrospinal Fluid. 1926, Chap. xi, p. 159.

7. Weed, L. H., Physiol. Rev., 1933, xii, 80. Positional Adjustments of the Pressure of the Cerebrospinal Fluid.

8. Weed, L. H., and Hughson, W., Am. J. Physiol., 1921-22, lviii, 101. Intracranial Venous Pressure and Cerebrospinal Pressure as Affected by the Intravenous Injection of Solutions of Various Concentrations.

9. Harrison, T. R., Calhoun, J. A., Cullen, G. E., Wilkins, W. E., and Pilcher, C., J. Clin. Invest., 1932, xi, 133. Studies in Congestive Heart Failure. XV. Reflex Versus Chemical Factors in the Production of Rapid Breathing.

10. Harrison, T. R., Harrison, W. G., Jr., Calhoun, J. A., and Marsh, J. P., Arch. Int. Med., 1932, 1, 690. Congestive Heart Failure. XVII. The Mechanism of Dyspnea on Exertion. 